\title{
Coal Displacement and Air Pollution: Evidence from China's "2+26" Cities Environment Policy
}

\author{
Meng Liu \\ $\mathrm{PhD}$ Student \\ School of Economics \\ Central University of Finance and Economics \\ 39 South College Rd., Beijing 10081, China.
}

\begin{abstract}
In order to solve the environmental problems in the Beijing-Tianjin-Hebei and surrounding areas during the heating season, the Chinese government issued Coal displacement policy in the " $2+26$ " cities in the area. This research uses the environmental data from " $2+26$ " cities and 25 surrounding cities during the period from 2015 to 2018, employing Different-In-Different research methods to analyze the environmental improvement effect by the policy in the area. We find that the policy makes significant impact on improvement of air condition in the " $2+26$ " cities during the heating season.
\end{abstract}

Keywords: Environmental policy; Coal displacement; Air pollution; Different-In-Different method.

\section{Introduction}

At the end of February 2017, China's Ministry of Environmental Protection, the National Development and Reform Commission and other departments jointly issued the 《Beijing-Tianjin-Hebei and surrounding areas 2017 air pollution prevention and control work program》. The program requires " $2+26$ " cities to comprehensively promote clean heating in winter, in which Beijing, Tianjin, Langfang and Baoding completed the "Coal-free Zone" construction task by the end of October. Other cities of the " $2+26$ " cities are required to complete more than 50,000 to 100,000 households coal replacement by the end of October. In some industries, industrial enterprises have implemented peak shifting production during the heating season. According to the requirements, by the end of October, the " $2+26$ " city will complete more than 3 million coals users by gas and electricity. More than 4 million users have actually completed, far exceeding the national plan. Hebei Province plans to change 1.8 million households and actually complete 2.5 million households. This paper attempts to test the effect of the coal displacement on the air quality improvement of the " $2+26$ " city. The "Coal displacement" program is an command-and-control environmental policy. Command-and-control environmental regulation refers to laws, regulations and policies on environmental protection formulated by government departments or environmental protection agencies. Mandatory is its main feature. These tools set legal standards for environmental technology, environmental performance and ecological outcomes, emphasizing that the government achieves environmental goals by imposing legal obligations or prohibitions on market entities, ie economic or administrative penalties for polluters who fail to meet and meet environmental requirements. Controlled tools mainly include: bans, technical standards, emission standards and emission limits. These tools have a strong regulatory role by penalizing market entities for failing to meet environmental standards and changing the return on investment of market players, but their role is sometimes considered to be inferior to that of market-based instruments (Lin et al, 2018). There are many studies on the environmental impact path of environmental policy, and some studies think about the influence on pollution transfer (Wei, 2011), some analyses ecological technology innovation effect ( $\mathrm{Li}, 2013)$. This paper will study the impact of " $2+26$ " environmental policy from the perspective of policy on environmental quality, that is, policy outcomes.

\section{Data}

This paper relies on the daily environmental report of more than 300 cities in 2015-2018 issued by the Ministry of Ecology and Environment, in which " $2+26$ " cities adopting the coal restriction policy in this paper are selected. In order to compare the effect of the policy, this paper chooses to compare the environmental quality data of the " $2+26$ " cities and 25 surrounding cities (Control group city) that are geographically adjacent to the implementation policy city. The environmental data includes six major pollutants of PM10, PM2.5, CO, CO\#, O\$, and SO\# as well as the Integrated Air Quality Index (AQI). Different and single pollutant indicators, AQI data comprehensively consider six different pollutant data. 
The calculation process first calculates the respective air quality sub-indices by different concentration standards of the six major pollutants, and then selects the sub-index of the primary pollutants of the day with the largest sub-index as the comprehensive air quality index (AQI), so the AQI index It can be seen as the overall quality of local air quality. Since the six pollutants emitted by burning natural gas will have different degrees of reduction than coal, the primary pollutants in different cities will vary from day to day. Therefore, this paper will mainly conduct empirical research with the Comprehensive Air Quality Index (AQI). The higher the AQI, the worse the air quality.

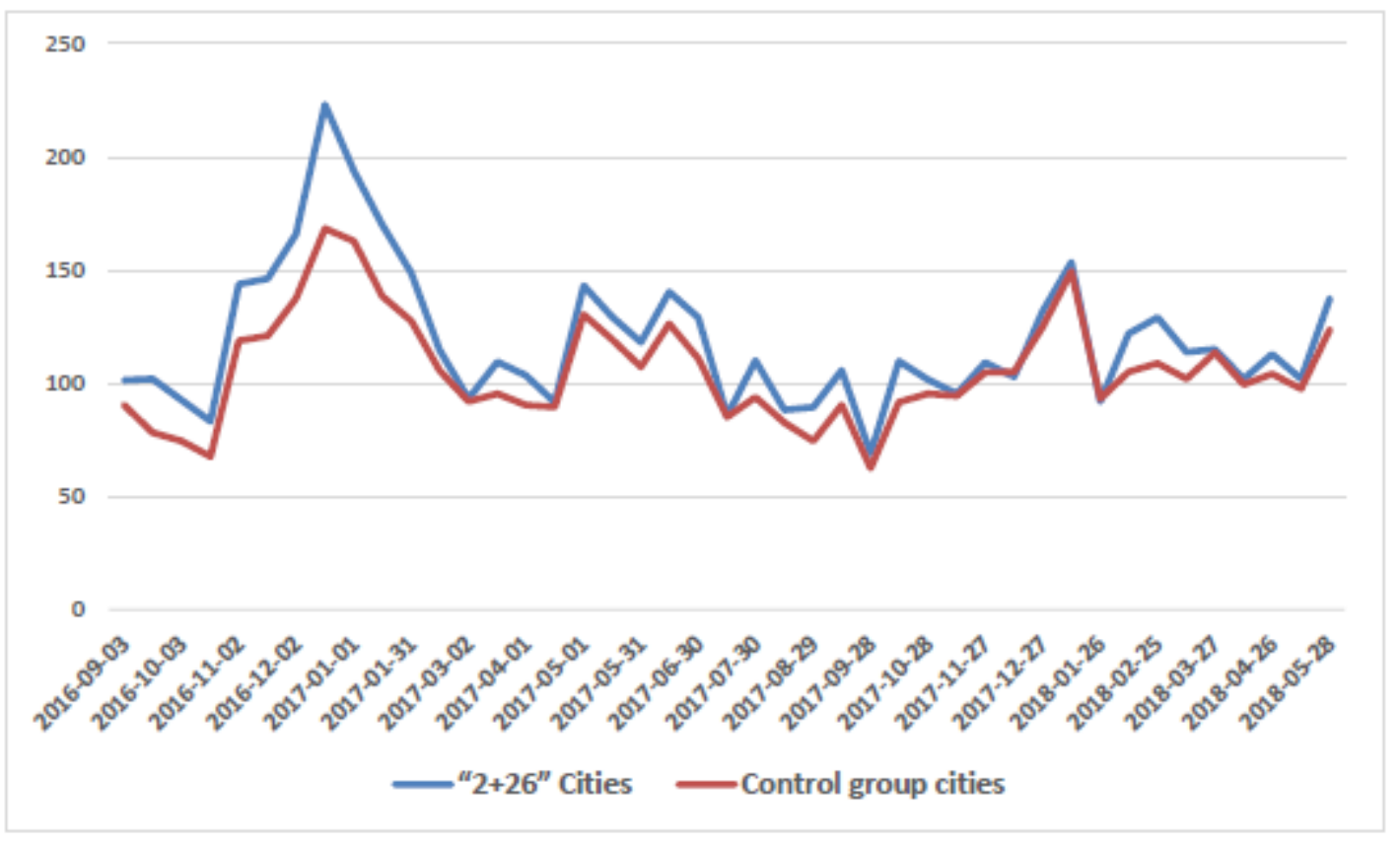

Figure 1, AQI index trend of " $2+26$ " and surrounding cities in 2016-2018

Weather conditions are also an important factor affecting air quality. For example, PM10 and PM2.5 values are susceptible to wind speed factors, and $O \$$ is less generated in cloudy, cold, and rainy weather. Therefore, this paper also collects the highest temperature, the lowest temperature, the wind speed grade and the weather data of rain and snow in each city during this period, and considers it in the research process. Table 1 presents the summary statistics of key variables.

Table 1, Summary statistics of " $2+26$ " and surrounding cities in 2014-2018 Summary statistics

\begin{tabular}{|c|c|c|c|c|c|c|c|c|}
\hline \multicolumn{2}{|c|}{ Variable (Mean) } & \multirow{2}{*}{$\begin{array}{l}\text { Sample } \\
\text { size } \\
995\end{array}$} & \multirow{2}{*}{$\begin{array}{l}\begin{array}{l}\text { Heating } \\
\text { season }\end{array} \\
995\end{array}$} & \multirow{2}{*}{$\begin{array}{l}\text { AQI } \\
160\end{array}$} & \multirow{2}{*}{$\begin{array}{r}\begin{array}{r}\text { Maximum } \\
\text { wind speed }\end{array} \\
3.45\end{array}$} & \multirow{2}{*}{$\begin{array}{l}\text { Highest } \\
\text { temperature } \\
8.29\end{array}$} & \multirow{2}{*}{$\begin{array}{r}\text { Rainning } \\
9 \%\end{array}$} & \multirow{2}{*}{$\begin{array}{r}\text { Snowing } \\
0.60 \%\end{array}$} \\
\hline \multirow{2}{*}{2014} & $" 2+26 "$ cities & & & & & & & \\
\hline & Control group cities & 686 & 686 & 121 & 3.68 & 7.67 & $8 \%$ & $0.90 \%$ \\
\hline \multirow{2}{*}{2015} & $" 2+26^{\prime \prime}$ cities & 9491 & 3147 & 120 & 3.39 & 19.2 & $20 \%$ & $2.60 \%$ \\
\hline & Control group cities & 9126 & 3026 & 104 & 3.47 & 18.66 & $24 \%$ & $3.20 \%$ \\
\hline \multirow{2}{*}{2016} & "2+26" cities & 9517 & 3173 & 116.5 & 2.94 & 19.16 & $22 \%$ & $3.07 \%$ \\
\hline & Control group cities & 9152 & 3051 & 101.59 & 3.11 & 18.64 & $26 \%$ & $3.25 \%$ \\
\hline \multirow{2}{*}{2017} & $" 2+26^{\prime \prime}$ cities & 9491 & 3147 & 116.6 & 2.8 & 19.7 & $20 \%$ & $2.12 \%$ \\
\hline & Control group cities & 9339 & 3056 & 103.87 & 3.12 & 19.15 & $24 \%$ & $2.45 \%$ \\
\hline \multirow{2}{*}{2018} & $" 2+26 "$ cities & 3874 & 1925 & 116.1 & 2.96 & 15.2 & $14 \%$ & $5 \%$ \\
\hline & Control group cities & 3726 & 1876 & 108.28 & 3.01 & 14.6 & $17 \%$ & $5.60 \%$ \\
\hline
\end{tabular}

\section{Model}

The heating seasons of the 53 cities selected in this paper are basically from November 15 of the current year to 24 o'clock on March 15 of the following year. Some cities may extend the heating season appropriately according to local temperature conditions. For example, the heating season in Beijing 2017-18 is extended to March 20, 2018, but the length of heating season is similar. 
Since the coal-restricting policy studied in this paper is mainly for the heating season, the urban air quality will generally decrease significantly after the heating season begins. Therefore, this paper mainly tests the impact of this policy factor on the heating season. The main model of this paper is as

follows:

$\mathrm{P}^{\prime}\left(=\alpha++\beta+*\right.$ Policy4' $\left(5+\beta \# *\right.$ Heating $+\beta \$ *$ Policy4' $\left(5 *\right.$ Heating $*$ Policy_year $+\gamma \mathrm{W}^{\prime}\left(+\mathrm{f}(\mathrm{t})+\varepsilon^{\prime}(\right.$

Where $\mathrm{P}^{\prime}($ is dependent variable is the logarithm of AQI in city $\mathrm{i}$ and on day t. $\alpha+$ is fixed effect, controlling for unobserved, time-unvarying city attributes that affect air quality.Policy_city is a dummy variable for the city under the policy, Heating is a dummy variable for days during heating period, Policy_city $*$ Heating $*$ Policy_year is the interpretation that this research concerned. $\mathrm{W}^{\prime}($ is a vector of daily weather variables for city $\mathrm{i}$ on day $\mathrm{t}$ including maximum wind speed, snowing or raining, average humidity, and average temperature. $f(t)$ is a flexible polynomial time trend term controlling for other unobserved factors that may affect daily air quality.

\section{Results}

We estimate the Model for the samples during 2014-2018. Table 2 presents the results: (1)Regardless of the heating period the average air condition in the " $2+26$ " cities, where implement the Coal displacement policy, is worse than cities in the comparing group.(2) level of AQI in all the 53 cities significant ispositively correlated with heating period.(3) Air condition is clearly affected by weather that the days in windy, raining, snowing have lower level of AQI. (4) the most important term in this study is Policy_Heating_year, which show that the Coal displacement implemented during the heating period have decreased the AQI level and improved air condition.

Table 2: the policy effect for " $2+26$ " citied during heating period

\begin{tabular}{|c|c|c|c|c|c|c|c|}
\hline \multirow[t]{2}{*}{ Linear regression } & & & \multicolumn{2}{|c|}{$\begin{array}{l}\text { Number of obs } \\
F(8,65354) \\
\text { Prob > F } \\
\text { R-squared } \\
\text { Root MSE }\end{array}$} & $\begin{array}{l}= \\
= \\
= \\
= \\
=\end{array}$ & \multicolumn{2}{|c|}{$\begin{array}{r}65,363 \\
1010.41 \\
0.0060 \\
0.1330 \\
55.078\end{array}$} \\
\hline & Coef. & $\begin{array}{l}\text { Robust } \\
\text { Std. Err. }\end{array}$ & t & $P>|t|$ & $195 \%$ & Conf. & Interval! \\
\hline Policy & 16.11746 & .4528274 & 35.59 & 0.000 & 15.22 & 2992 & 17.005 \\
\hline Heating & 54,3053 & .7710787 & 70.43 & 0.000 & 52.79 & 9399 & 55.81662 \\
\hline Policy_Heating_year & -30.75276 & 1.183999 & -25.97 & 0.000 & -33.0 & 9734 & -28.43213 \\
\hline highten & .9585878 & .0277243 & 34.58 & 0.000 & .9042 & 2481 & 1.012927 \\
\hline rainyes & -11.75013 & .4691831 & -25.04 & 0.000 & -12.66 & 5973 & -10.83053 \\
\hline snowyes & -.3884642 & 1.562289 & -0.25 & 0.804 & -3.450 & 551 & 2.673622 \\
\hline windrank & -5.707625 & .2468232 & -23.12 & 0.000 & -6.191 & 1398 & -5.223851 \\
\hline 1. Year & -2.425038 & .4171528 & -5.81 & 0.000 & -3.242 & 2657 & -1.607418 \\
\hline _cons & 89.01898 & 1.201521 & 74.09 & 0.000 & 86.66 & 5399 & 91.37396 \\
\hline
\end{tabular}

\section{Conclusion}

This study analyses effect of the Coal displacement policy in the " $2+26$ " cities in China. We find that the air condition of the cities have been clearly improved by implement of this policy. According to the research by Peng et al (2018), the " $2+26$ " cities' Coal displacement policy force many high-polluted small factories reducing its production, those factories have low profit and lead to high environmental damage. This research proves that the policy could improve these cities' air condition, and provides a timely and useful reference to the policymakers of other cities.

\section{References}

Lin Feng, Xu Yue, Zhang Xionglin. 2016. "The effect of the environmental policy instruments on eco-innovation." Science \& Technology Progress and Policy.2018(14)

Jing Weimin, Zhanglu. 2014. "Environmental Regulation, Open-up strategy and Green Technology Progress of Chinese Industry." Economic Research Journal.2014(09)

PENG Fei,YU Fang,MA Guoxia.2018. "Analysisof social-economic benefits and environmental pollution control costs of'Dispersed, Disrupted and Polluted' enterprises in the '2+26'region".Research of Environmental Sciences.2018(31)

Ma Limei, Zhang Xiao.2014."The spatial effect of China's haze pollution and the impact from economic change and energy structure”. China Industrial Economics.2014(4)

Wei Wei, Bi Chao.2011.“Environmental Regulation, Inter-regional Industrial Transfer and Pollution Refuge Effect”. Journal of Shanxi University of Finance \& Economics.2011(8)

Li Wanhong,Bi Kexin,Cao Xia.2013.“ The Impact of Environmental Regulation Tools on Green Technology Innovation of Manufacturing Enterprises".2013(10) 